\title{
On-Line Self-Calibrating Single Crystal Sapphire Optical Sensor Instrumentation for Accurate and Reliable Coal Gasifier Temperature Measurement
}

\section{Semi-Annual Technical Progress Report}

Reporting Period Start Date: 1 April 2003

Reporting Period End Date: 30 September 2003

Principal Authors: Kristie Cooper, Gary Pickrell and Anbo Wang

Report Issued: November 2003

DOE Award Number: DE-FC26-99FT40685

Submitted by: Center for Photonics Technology

Bradley Department of Electrical Engineering

Virginia Polytechnic Institute \& State University

Blacksburg, VA 24061-0111

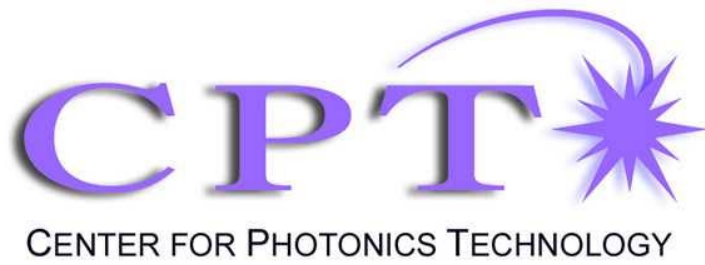




\section{Disclaimer:}

This report was prepared as an account of work sponsored by an agency of the United States Government. Neither the United States Government nor any agency thereof, nor any of their employees, makes any warranty, express or implied, or assumes any legal liability or responsibility for the accuracy, completeness, or usefulness of any information, apparatus, product, or process disclosed, or represents that its use would not infringe privately owned rights. Reference herein to any specific commercial product, process, or service by trade name, trademark, manufacturer, or otherwise does not necessarily constitute or imply its endorsement, recommendation, or favoring by the United States Government or any agency thereof. The views and opinions of authors expressed herein do not necessarily state or reflect those of the United States Government or any agency thereof. 


\begin{abstract}
This report summarizes technical progress over the second six month period of the Phase II program "On-Line Self-Calibrating Single Crystal Sapphire Optical Sensor Instrumentation for Accurate and Reliable Coal Gasifier Temperature Measurement", funded by the Federal Energy Technology Center of the U.S. Department of Energy, and performed by the Center for Photonics Technology of the Bradley Department of Electrical and Computer Engineering at Virginia Tech.

The outcome of the first phase of this program was the selection of broadband polarimetric differential interferometry (BPDI) for further prototype instrumentation development. This approach is based on the measurement of the optical path difference (OPD) between two orthogonally polarized light beams in a single-crystal sapphire disk. The objective of this program is to bring the BPDI sensor technology, which has already been demonstrated in the laboratory, to a level where the sensor can be deployed in the harsh industrial environments and will become commercially viable.

Research efforts were focused on evaluating corrosion effects in single crystal sapphire at temperatures up to $1400^{\circ} \mathrm{C}$, and designing the sensor mechanical packaging with input from Wabash River Power Plant. Upcoming meetings will establish details for the gasifier field test.
\end{abstract}




\section{Table of Contents}

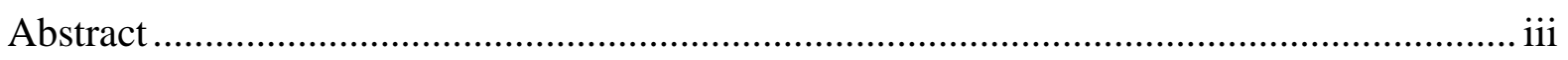

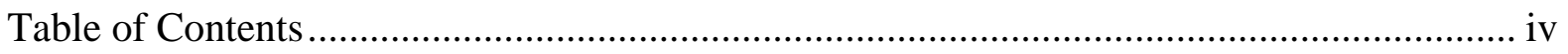

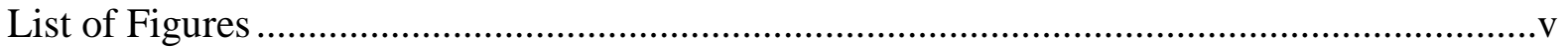

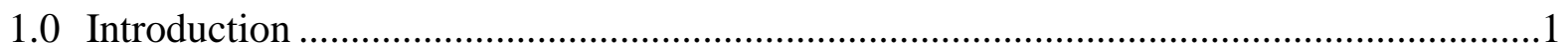

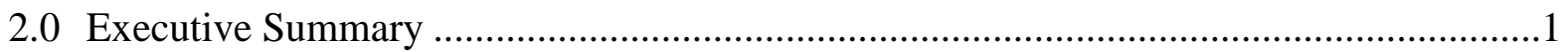

\section{EXPERIMENTAL}

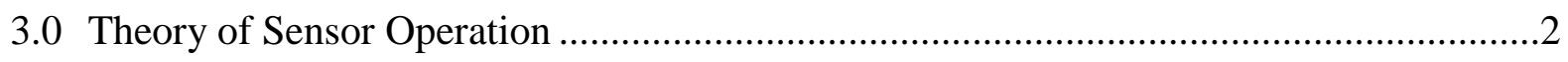

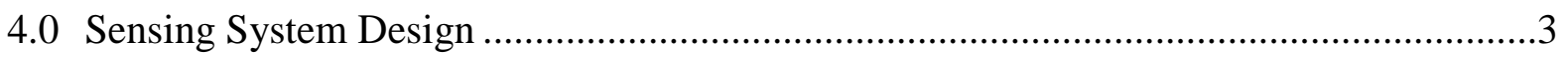

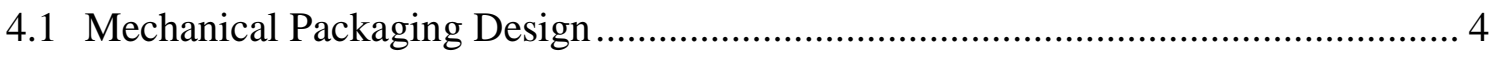

\section{RESULTS AND DISCUSSION}

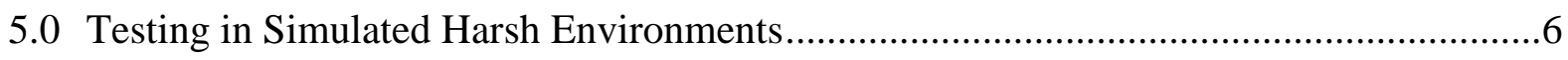

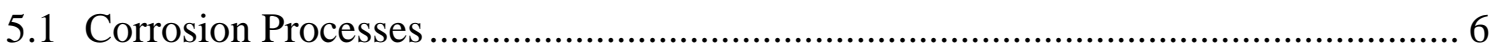

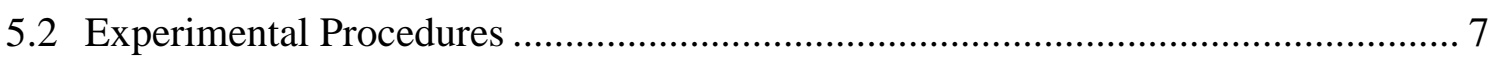

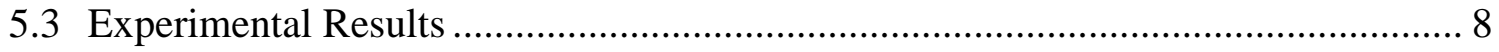

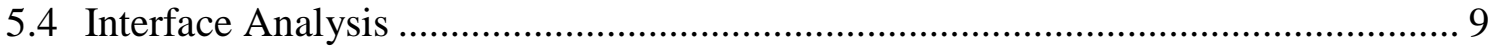

\section{CONCLUSION}

6.0 Conclusions and Future Work .......................................................................... 12

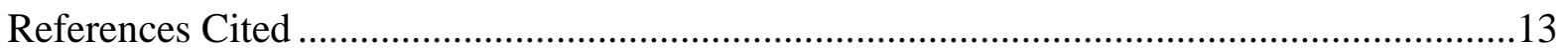

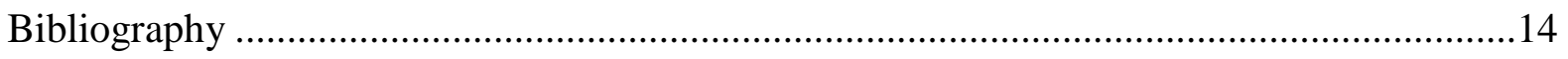

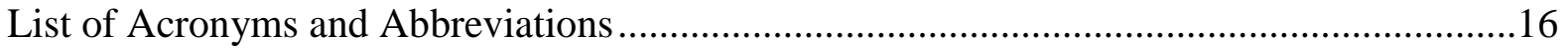




\section{List of Figures}

Figure 3.1. Schematic of the single-crystal sapphire based optical high temperature sensor... 3

Figure 4.1. Phase II approach ........................................................................................ 4

Figure 4.2. Sensor probe mechanical packaging scheme (units in $\mathrm{mm}$ ).............................. 5

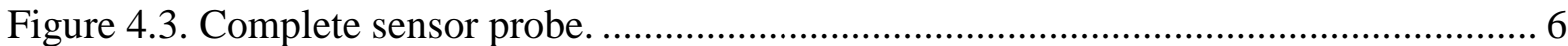

Figure 5.1. Corrosion of sapphire in coal slag at $1200^{\circ} \mathrm{C}$ over 4 days................................... 9

Figure 5.2. Corrosion of sapphire in coal slag at $1300^{\circ} \mathrm{C}$ over 4 days.................................... 9

Figure 5.3. Sapphire in coal slag after heat treatment and dissolution of coal slag in HF...... 10

Figure 5.4. Sapphire in coal slag at $1200^{\circ} \mathrm{C}$ for two days................................................ 11

Figure 5.5. EDX image of sapphire in coal slag at $1200^{\circ} \mathrm{C}$ for 2 days, analyzing $\mathrm{Si}$ (upper left), $\mathrm{Fe}$ (upper right), $\mathrm{Al}$ (lower left) and $\mathrm{O}$ (lower right). ................................... 11 


\subsection{Introduction}

In the first phase of this program, five different optical temperature sensing schemes were thoroughly investigated to determine an optimal approach for high temperature measurement in coal gasification systems. Based on comparative evaluation and analysis of the experimental results, the broadband polarimetric differential interferometry (BPDI) was chosen for further prototype instrumentation development. This approach is based on the self-calibrating measurement of the optical path difference (OPD), i.e. phase retardation between the two orthogonally polarized light beams in a single-crystal sapphire disk, which is a function of both the temperature dependent birefringence and the temperature dependent dimensional sizes.

In the past half-year, efforts were focused on designing the sensor mechanical packaging and evaluating the sapphire corrosion in coal slag at operating temperatures. Three packaging versions were developed and downselected to one based on input from Wabash River Power Plant. Meetings scheduled for late October will finalize details for sensor testing. Corrosion properties of sapphire in coal slag were evaluated at temperatures up to $1400^{\circ} \mathrm{C}$, demonstrating that single crystal sapphire is resistant to coal slag penetration at high temperature.

\subsection{Executive Summary}

This report summarizes the technical progress over the second six month period of the Phase II program "On-Line Self-Calibrating Single Crystal Sapphire Optical Sensor Instrumentation for Accurate and Reliable Coal Gasifier Temperature Measurement", funded by the Federal Energy Technology Center of the U.S. Department of Energy, and performed by the Center for Photonics Technology of the Bradley Department of Electrical and Computer Engineering at Virginia Tech.

During the reporting period, research efforts under the program were focused on the following.

- Development of the mechanical packaging for the sensor in cooperation with the Wabash River Power Plant.

Packaging supports and aligns the optical components, as well as protects them from the hostile environment. The sensor is expected to survive a minimum of 45 days in an average $2600 \mathrm{~F}, 400 \mathrm{psig}$ and highly corrosive environment. Three packaging versions were developed, and one jointly selected with Global Energy Technology's 
Wabash River Facility. Meetings are scheduled in October to finalize packaging and testing details.

- Analysis of sapphire corrosion in coal slag at temperatures up to $1400^{\circ} \mathrm{C}$

Corrosion processes in ceramics are complex and vary greatly with both the physical and chemical properties of the material and the environment to which they are subjected. The amount of data available in the literature is very limited. Coal constituents such as alkali, sulfur and transition metals together with hot steam contribute to the corrosive environment in the gasifier. Temperature measurements in coal gasifiers require materials that are resistant to the corrosive coal slag at temperatures as high as $1400^{\circ} \mathrm{C}$. Experiments demonstrated that sapphire is resistant to slag penetration at high temperature with minimal degradation. The reaction at the interface and steps of dissolution of sapphire are analyzed using SEM and EDAX micrographs.

Efforts during the coming months will focus on further laboratory testing and calibration of the field ready sensor prototype design, completion of corrosion testing, and site preparation and installation for the gasifier field test.

\subsection{Theory of Sensor Operation}

The working principle of the broadband polarimetric differential interferometric (BPDI) sensing system is shown in Figure 3.1.The broadband light from a high power light emitting diode is injected into a multimode optical fiber and propagates through a two by two fiber coupler to the sensor head. The light is first converted into a linearly polarized collimated optical beam and travels across a free space enclosed by a high temperature ceramic tube and a single crystal sapphire tube to a single crystal sapphire disk, functioning as the sensing element. The sapphire disk is arranged such that the linear polarization is at $45^{\circ}$ with respect to the fast and slow axes of the crystal. After passing through the sapphire disk, the two linear polarization components along the fast and slow axes experience a differential phase delay due to the sapphire birefringence. The light, containing the two different linear polarization components, is then reflected by a right angle zirconia prism and passes through the sapphire sensing element again, so the differential phase retardation is doubled. The two linear components with a differential phase delay are then combined along the polarizer direction to interfere with each other. The light is then collected by the same input optical fiber and travels back along the same fiber and through the same coupler to the optical detection end. The returned light intensity can be expressed as

$$
I(\lambda)=2 k I_{S}(\lambda)\left(1+\cos \left(\frac{2 \pi d(T) \Delta n(T)}{\lambda}\right)\right),
$$

where $I_{S}(\lambda)$ is the spectral power distribution which is a function of the wavelength $(\lambda)$ of the broadband light source; $k$ is a parameter describing the power loss of the optical system, and 
can be treated as a constant; $d$ is the thickness of the sapphire disk; and $\Delta n=n_{o}-n_{e}$ is the birefringence of the sapphire disk. Both $d$ and $\Delta n$ are functions of the temperature $T$. From this equation, it can be seen that the output spectral density is a function of the light wavelength and the differential phase delay, which is a function of temperature. It is therefore possible to extract the temperature information by measuring the output optical spectrum.

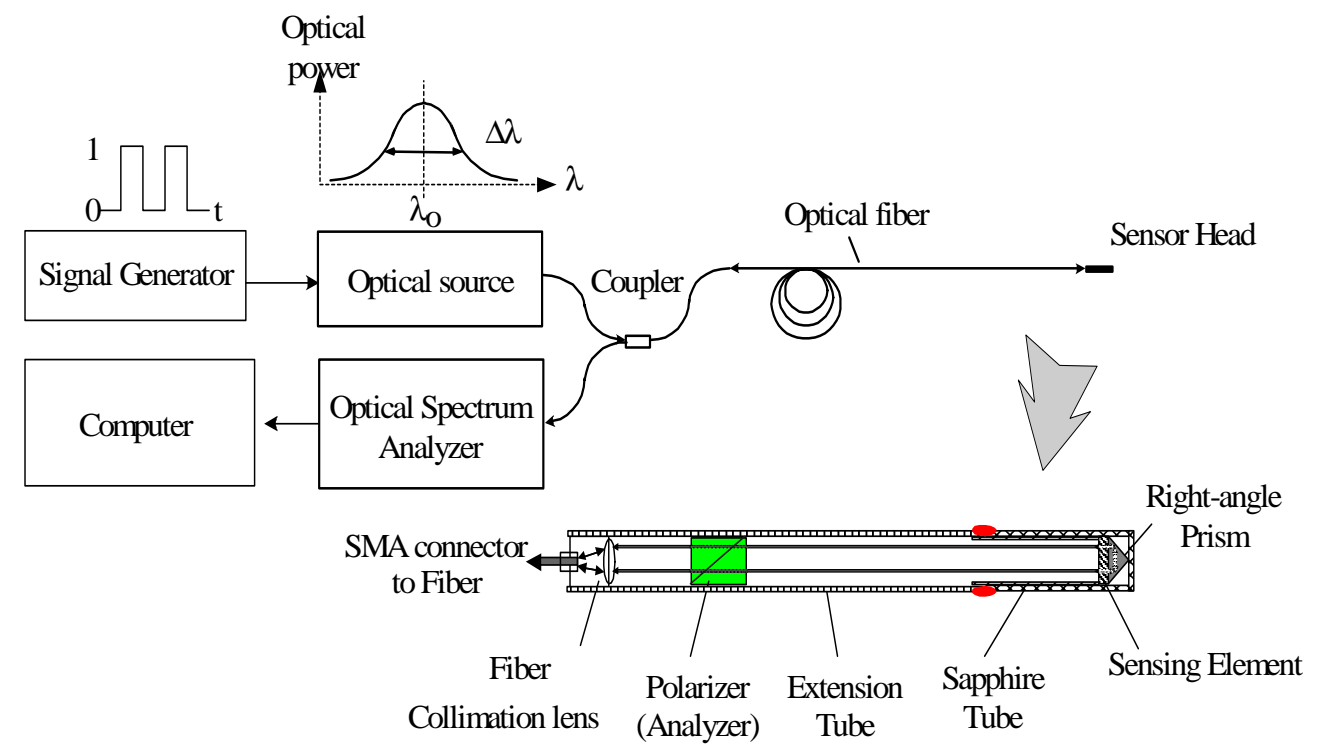

Figure 3.1. Schematic of the single-crystal sapphire based optical high temperature sensor.

\subsection{Sensing System Design}

In Phase I of the project the sapphire-based BPDI optical sensor was successfully demonstrated for the measurement of temperature over a wide range (room temperature up to $2600 \mathrm{~F}$ ) with repeatability of $\pm 2.5^{\circ} \mathrm{C}$, accuracy of $\pm 6^{\circ} \mathrm{C}$, long-term drift of $\pm 2^{\circ} \mathrm{C}$ and resolution of about $0.07^{\circ} \mathrm{C}$. Current efforts are focused on developing the mechanical packaging for the sensor and testing it at the Wabash River Power Plant, as illustrated in Figure 4.1. The mechanical packaging serves two purposes: first, to protect the optical components from the hostile environment, and second, to support and align the optical components. The sensor is expected to survive a minimum of 45 days in an average $2600 \mathrm{~F}$, 400psig and highly corrosive environment.

During the reporting period, we developed three packaging versions. After setting up communication with Wabash River Power Plant, one version of the design was recently selected. Meetings are scheduled at Wabash River in late October to examine the mounting nozzles for future sensor deployment, to finalize the mechanical packaging design, and to discuss the potential for long distance data acquisition, which will be an important issue in sensor testing. 


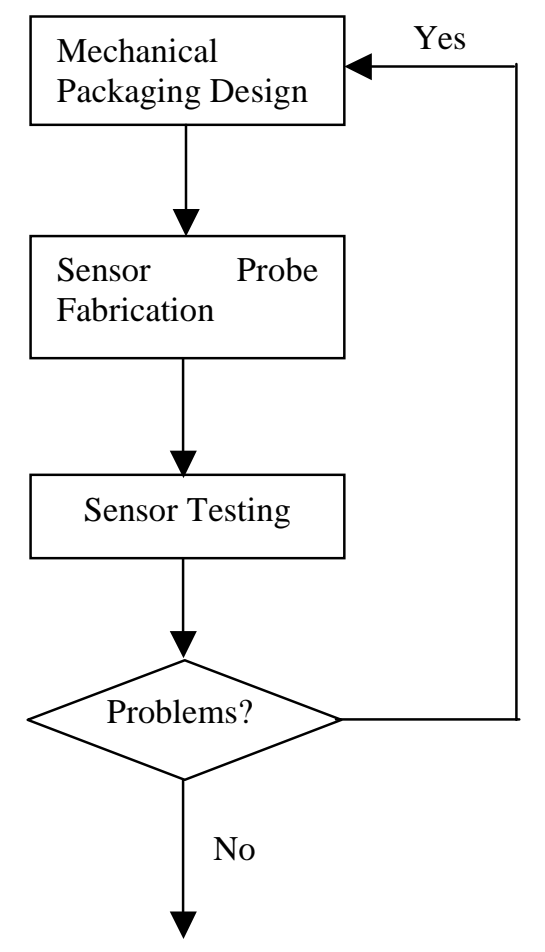

Figure 4.1. Phase II approach

\subsection{Mechanical Packaging Design}

Based on our current knowledge, three candidate nozzles on the reactor would be appropriate for testing, namely, [X1], [X2], and [X5] which are located on the upper section of the (horizontal) $1^{\text {st }}$ stage reactor or at the bottom (just upstream) of the entry into the (vertical) $2^{\text {nd }}$ stage reactor. All of the locations are equivalent in that they would expose the inserted probe to the $1^{\text {st }}$ stage reactor gases, and all are currently available, i.e. blinded, and relatively accessible. The configuration of all three nozzles is indicated in the table below.

Table 4.1. Candidate nozzle characteristics.

\begin{tabular}{|c|c|c|c|}
\hline Nozzle Characteristic & Nozzle [X1] & Nozzle [X2] & Nozzle [X5] \\
\hline Size/rating, in/\# $\{1\}$ & 4" / 300\# & 4" / 300\# & 4" / 300\# \\
\hline Type $\{2\}$ & RFLWN & RFLWN & RFLWN \\
\hline Projection, in $\{3\}$ & 8” $[204 \mathrm{~mm}]$ & 8” $[204 \mathrm{~mm}]$ & 8"' [204mm] \\
\hline Shell thickness, in & 7 1/2” [192mm] & 7 1/2” [192mm] & 2 3/4" [70mm] \\
\hline Refractory thickness & $\begin{array}{l}1^{\prime}-81 / 4 " \\
{[517 \mathrm{~mm}]}\end{array}$ & $\begin{array}{l}1^{\prime}-81 / 4 " \\
{[517 \mathrm{~mm}]}\end{array}$ & $2^{\prime}-5^{\prime \prime}[741 \mathrm{~mm}]$ \\
\hline Location on Reactor & Top horiz. @ 45 & Top horiz.@45 & Top horiz. @ transition \\
\hline
\end{tabular}

Notes:

\{1\} All flanges are industry standard, conforming to ANSI B16.5. Data provided is nominal pipe size, 4" $[100 \mathrm{~mm}]$ and $300 \mathrm{psig}$ pressure class.

\{2\} RFLWN = Raised face, long weld neck.

$\{3\}$ Projection $=$ distance from vessel shell O.D. to flange face. 
The mechanical packaging design is shown in Figure 4.2. The sapphire outer protection tube (blue) is bonded with another sapphire inner prism holding tube (blue). The outer sapphire protection tube is directly exposed to the high temperature harsh environment. It protects the sensing sapphire prism from contamination and corrosion by coal slag. The inner sapphire tube serves two purposes: one is to mount the sensing sapphire prism (the machined triangular slot), the other is to give an extra layer of protection from the harsh environment. The inner sapphire tube is bonded with an alumina tube (brown), which supports the double sapphire tube while keeping the optical components aligned. The alumina tube and the sapphire tubes are bonded with high thermal expansion high temperature ceramic glue $(3000 \mathrm{~F})$, which prevents slag from reaching the sensing element. The CTE of the glue is chosen to match the CTE of the alumina tube and also the sapphire tubes so that under the thermal cycling the joint point will not break. A round high temperature nickel alloy tube (grey) is used to prevent the alumina tube from being crushed by the deformation of the refractory wall. The thickness is $5 \mathrm{~mm}$. Mineral wool paper is wrapped $2 \mathrm{~mm}$ thick around the alumina tube. It serves as a intermediate soft layer. The alumina tube is bonded with 2 short tubes that are threaded outside. The 2 short tubes are screwed into the high temperature nickel alloy tube as a stopper for the mineral wool paper. The nickel alloy tube is threaded outside, so that it can be screwed into the flange. The flange provides $25 \mathrm{~cm}$ long support for the tube. The output window is a piece of thick glass sealed to a through-hole on the flange. The flange is fastened to the metal wall of the coal gasifier with 4 screws. It is sealed with Oring. A metal tube with fiber collimator and polarizer is welded to the flange on the other side. Each of the optical components can be adjusted by 2 sets of screws. Additionally, the polarizer can be tuned with a knob.
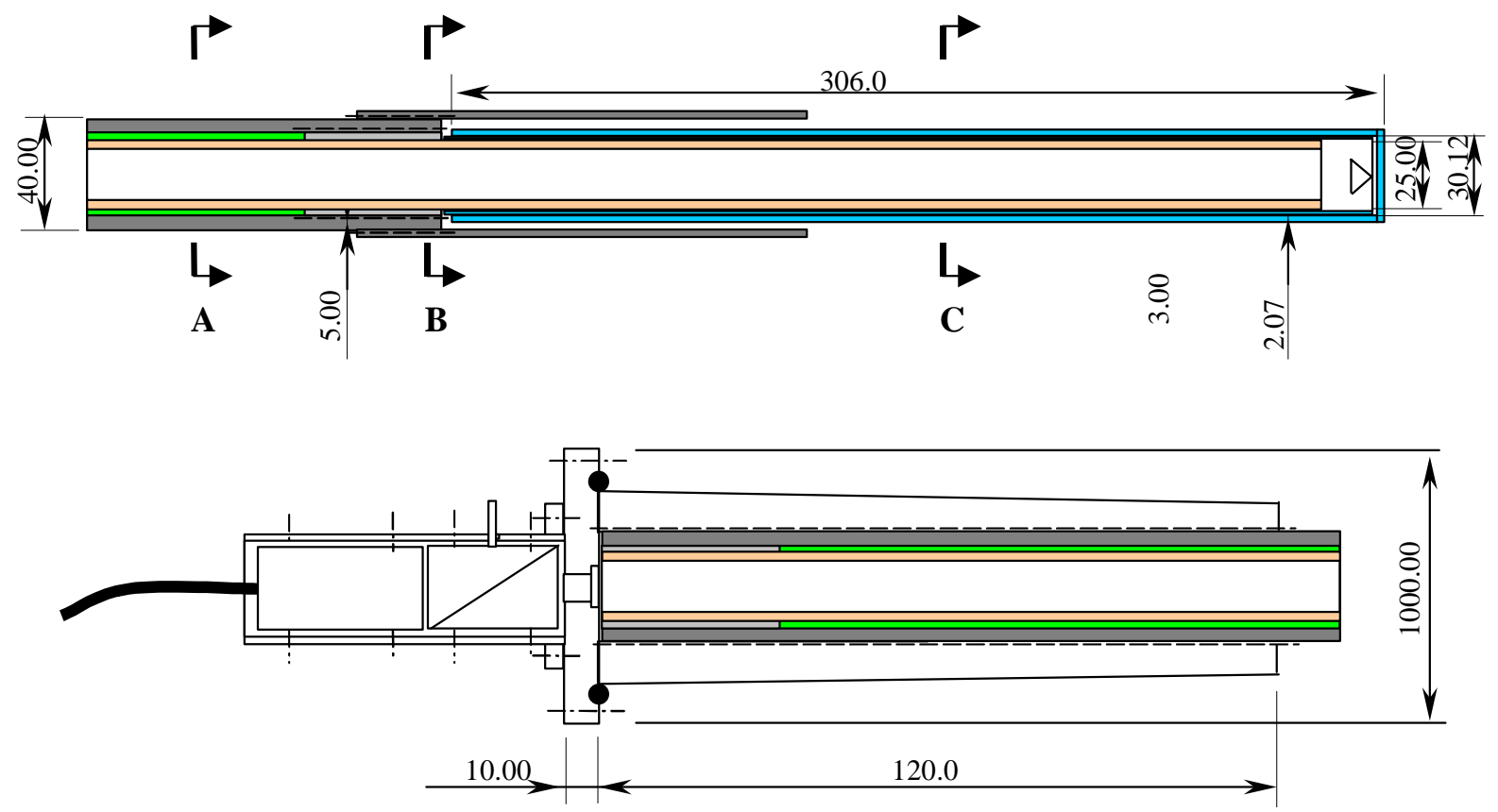

Figure 4.2. Sensor probe mechanical packaging scheme (units in mm). 
The overall sensor is shown in Figure 4.3. The sapphire tubing will protrude out of the refractive wall approximately $100 \mathrm{~mm}$. The space between the bore of the refractory wall and vessel shield and the sensor probe is padded with mineral wool to provide a cushion layer. The finalized mechanical packaging design will be available after the Wabash meeting.

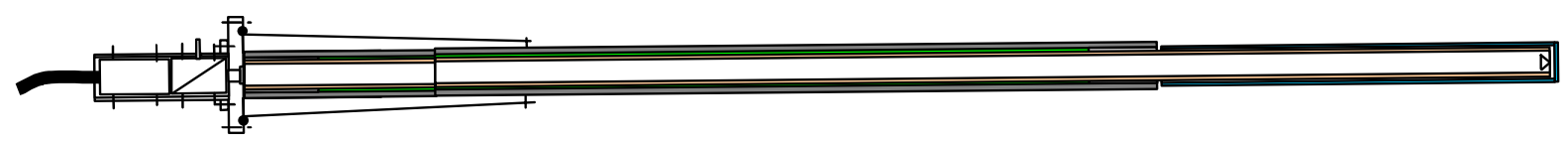

Figure 4.3. Complete sensor probe.

\subsection{Testing in Simulated Harsh Environments}

Monitoring temperature inside a coal gasifier is difficult due to the extremely harsh and corrosive environment. Coal constituents such as alkali, sulfur and transition metals together with hot steam contribute to this corrosive environment ${ }^{1}$. Temperature measurements require materials that are resistant to corrosive coal slag at temperatures as high as $1400^{\circ} \mathrm{C}$. Corrosion of sapphire in coal slag was measured at $1200^{\circ} \mathrm{C}, 1300^{\circ} \mathrm{C}$, and $1400^{\circ} \mathrm{C}$ for different time periods and corrosion rates determined. The reaction at the interface and steps of dissolution of sapphire are analyzed using SEM and EDAX micrographs.

\subsection{Corrosion Processes}

Corrosion is a key factor restricting the application of ceramics in some industries. Understanding corrosion processes and diffusion mechanisms in ceramic materials in various environments could significantly improve current uses and give rise to new applications. Considerable research has been done in this area to find suitable materials for coal gasification, coal liquefaction, battery storage, gas turbine power generation, fossil fuel processing and many other energy systems.

The extent of corrosion is very much dependent on the material structure, including crystal size and shape, porosity, and grain boundaries, which are common in structural ceramic materials. Pores and along grain boundaries are most vulnerable locations for slag attack. To minimize corrosion, these structural factors must be eliminated. This can be done by using single crystal.

Corrosion processes in ceramics are complex and vary greatly with both the physical and chemical properties of material, and the environment. A particular refractory material can be the most resistant in a specific environment under certain conditions, but if conditions change, another refractory might take its place. Even though much research has been performed on the corrosion of ceramics, the amount of available data is still limited. More 
information is necessary for complete understanding of corrosion processes and corrosion mechanisms.

Efforts during the reporting period concentrated investigation of corrosion of sapphire (single crystal alumina, $\mathrm{Al}_{2} \mathrm{O}_{3}$ ) in coal slag. Its chemical resistance in corrosive environments at high temperatures is superior to that of other refractory oxides. The experiments described here show that sapphire is resistant to slag penetration at high temperature with minimal degradation.

In considering the corrosion of a solid in liquid, both thermodynamics and kinetics must be taken into account. The corrosion process proceeds in stages, depending on the type of material and the environment. Corrosion can be controlled by diffusion or by the rate of reaction at the interface, depending on which is the rate controlling step. It is also possible for several stages to proceed simultaneously, e.g. transport of matter or energy to and from the interface and the reaction at the interface.

Since the corrosion process only takes place at the interface between the solid and liquid, this interface area is of great importance. Ferber and Tennery studied corrosion of ceramics in an oil-coal mixture ${ }^{2}$. Their analysis showed that corrosion of alumina occurs in two steps. First, the reaction of alumina and coal slag formed a reaction product layer at the interface. The second step was dissolution of this product in coal slag. The deterioration of alumina proceeds by alternation of those two steps. The reaction zone at the interface consisted of mostly $\mathrm{Al}$ and $\mathrm{Fe}$ and small amounts of $\mathrm{Ni}$. It is possible that this interface product was either iron spinel layer and iron-nickel aluminate compound. Earlier experiments of Wei and Tennery ${ }^{3}$ observed aluminosilicate deposit along the interface most likely due to the different composition of coal slag.

\subsection{Experimental Procedures}

A series of experiments was designed to qualitatively examine the corrosion resistance of single crystal sapphire in harsh environment.

\subsubsection{Material selection}

Single crystal sapphire plates, about $0.8 \mathrm{~mm}$ think, were used for all experiments. A suitable crucible size was $5 \mathrm{~mL}, 2.5$ x $1.6 \mathrm{~mm}$, made by CoorsTek.

\subsubsection{Heat treatment}

Single crystal sapphire plates were cut into smaller samples with a diamond saw. One of each sample was placed in $5 \mathrm{~mL}$ alumina crucible with coal slag and heated at $1200^{\circ} \mathrm{C}$, $1300^{\circ} \mathrm{C}$ and $1400^{\circ} \mathrm{C}$ for four different time periods: 1 day, 2 days, 3 days and 4 days in Deltech electronically-controlled furnace. Upon cooling, slices were cut from the crucibles that included the sapphire - coal slag interface. 


\subsubsection{Thickness measurements}

The thickness of the sapphire samples was measured before and after corrosion experiments. Their difference represents the amount of corrosion.

The initial thickness was measured simply with Vernier caliper. The final thickness, however, was more difficult to measure. Circular cross sections of the crucible, including the coal slag and sapphire, were placed in concentrated hydrofluoric acid until coal slag was dissolved. The sapphire pieces were then polished with $30 \mu$ alumina polishing paper to ensure that all of the coal slag was removed from its surface. The final thickness was also measured with Vernier caliper.

\subsection{Experimental Results}

The data shown in Table 5.1 indicates that very little or no corrosion occurs at $1200^{\circ} \mathrm{C}$ and $1300^{\circ} \mathrm{C}$. Ten measurements of each sample were taken, and the average of those measurements is reported.

Table 5.1. Corrosion of sapphire in coal slag at $1200^{\circ} \mathrm{C}$ and $1300^{\circ} \mathrm{C}$ over 4 days.

\begin{tabular}{|c|c|c|c|c|c|c|}
\hline & \multicolumn{3}{|c|}{$1200^{\circ} \mathrm{C}$} & \multicolumn{3}{c|}{$1300^{\circ} \mathrm{C}$} \\
\hline Days & initial & final & difference & initial & final & difference \\
\hline \hline 1 & 0.75 & 0.76 & $\mathbf{- 0 . 0 1}$ & 0.89 & 0.88 & $\mathbf{0 . 0 1}$ \\
\hline 2 & 0.8 & 0.81 & $\mathbf{- 0 . 0 1}$ & 0.79 & 0.8 & $\mathbf{- 0 . 0 1}$ \\
\hline 3 & 0.8 & 0.8 & $\mathbf{0}$ & 0.75 & 0.77 & $\mathbf{- 0 . 0 2}$ \\
\hline 4 & 0.89 & 0.88 & $\mathbf{0 . 0 1}$ & 0.89 & 0.9 & $\mathbf{- 0 . 0 1}$ \\
\hline
\end{tabular}

Figure 5.1 and Figure 5.2 represent the trend in sapphire corrosion in coal slag over 4 days at $1200^{\circ} \mathrm{C}$ and $1300^{\circ} \mathrm{C}$. The best fit lines for both $1200^{\circ} \mathrm{C}$ and $1300^{\circ} \mathrm{C}$ are quadratic, with $\mathrm{R}^{2}$ value of 0.9818 and 0.9895 respectively. The error bars indicate one standard deviation for each point. Some points have wider range of deviation than others. This is probably due to the final thickness measurement. In some cases, the sapphire piece broke into smaller pieces during the coal slag removal process, so that after the coal slag had been dissolved away with $\mathrm{HF}$, those pieces were measured separately giving a wider variation in the data. In other cases, the sapphire piece was able to be measured as a whole, and the final measurements are more in agreement to each other, e.g. 4 days at $1300^{\circ} \mathrm{C}$. This point has standard deviation of zero and therefore no error bars.

The measurement error is not due to the repeatability of the calipers but due to different amounts of corrosion at different locations on the sapphire samples. A standard deviation of zero was obtained from initial measurements of sapphire samples. Also, repetitive measurements of a single piece of corroded sapphire produced the same result. The variation in final data originates from measurements of sapphire pieces from the same sample. More corrosion appears to take place on the bottom portion of sapphire than on the top, which may have been caused by uneven consistency of coal slag. 


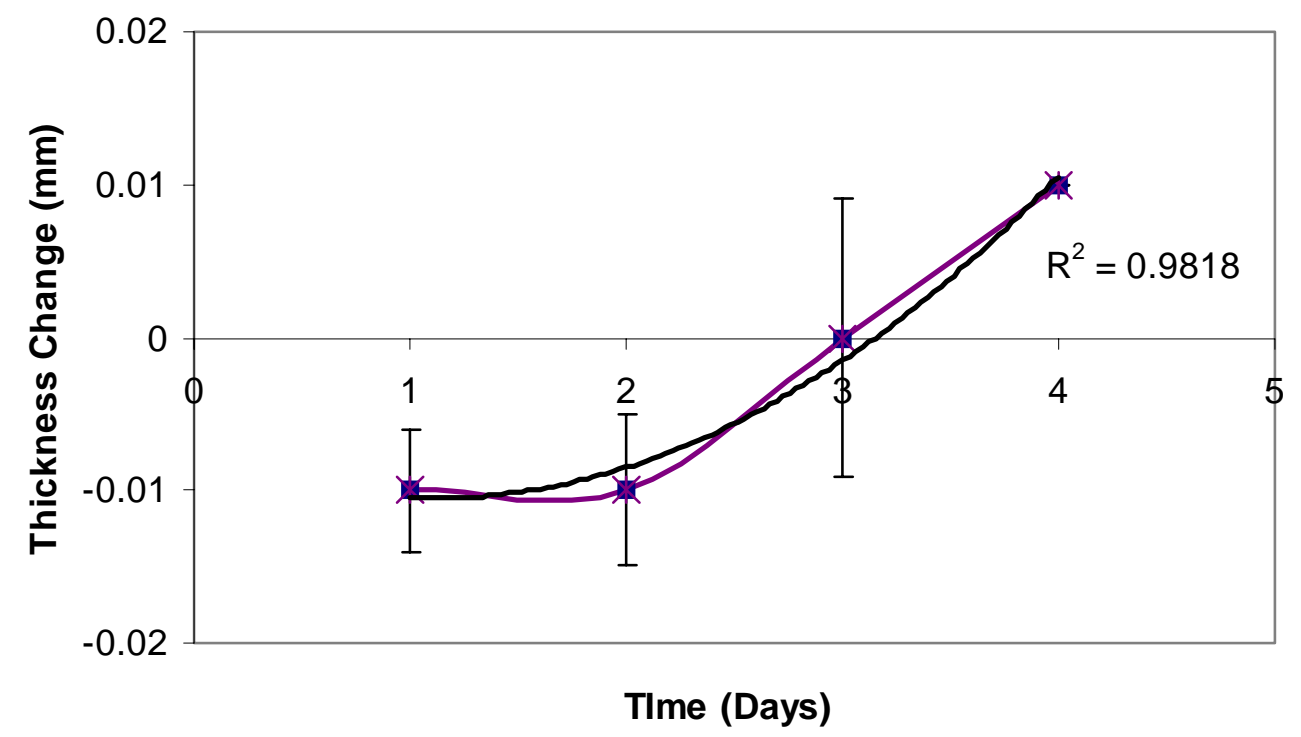

Figure 5.1. Corrosion of sapphire in coal slag at $1200^{\circ} \mathrm{C}$ over 4 days.

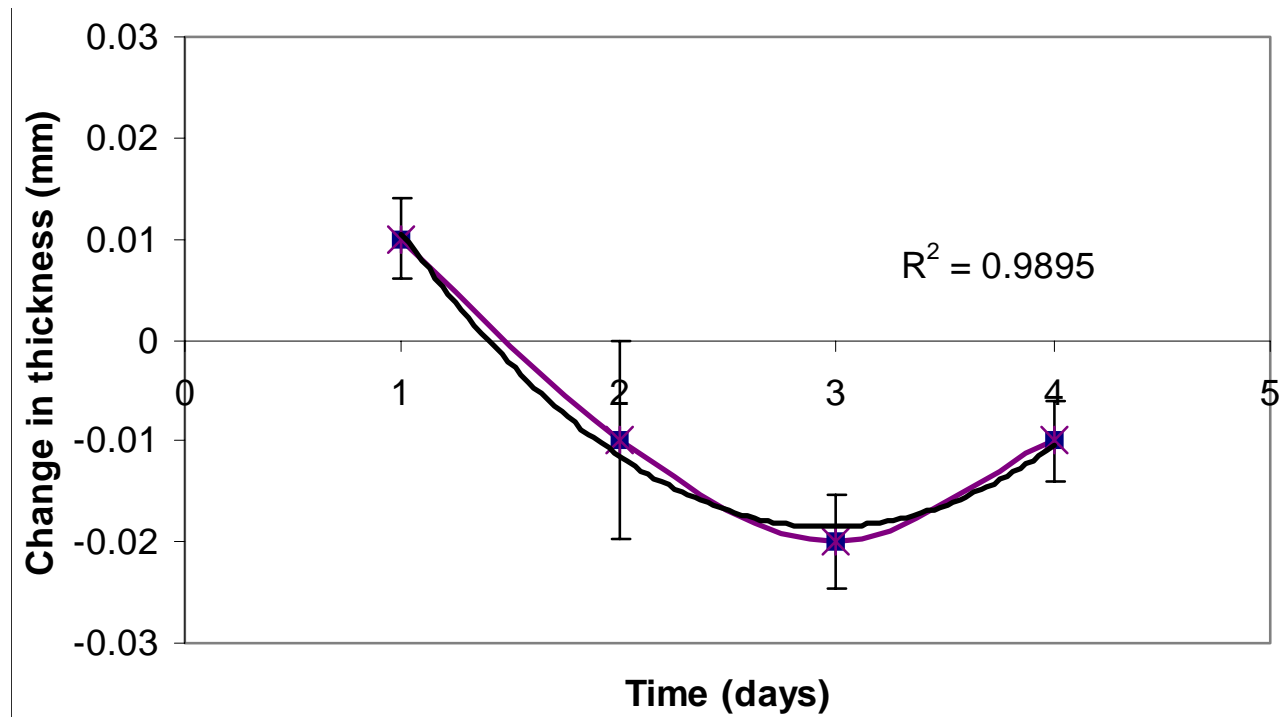

Figure 5.2. Corrosion of sapphire in coal slag at $1300^{\circ} \mathrm{C}$ over 4 days.

\subsection{Interface Analysis}

A representative sapphire sample in coal slag, after heat treatment and after the entire crucible was immersed in HF in order to dissolve coal slag, is shown in Figure 5.3. The sapphire portion that remains in the crucible is visibly cracked. The upper portion broke off and was used to take final thickness measurements. It was also cracked but not as much as the portion shown in the picture. Coal slag remains at the bottom of the crucible, around the sapphire; it is yellowish in color and it contains some air bubbles. 


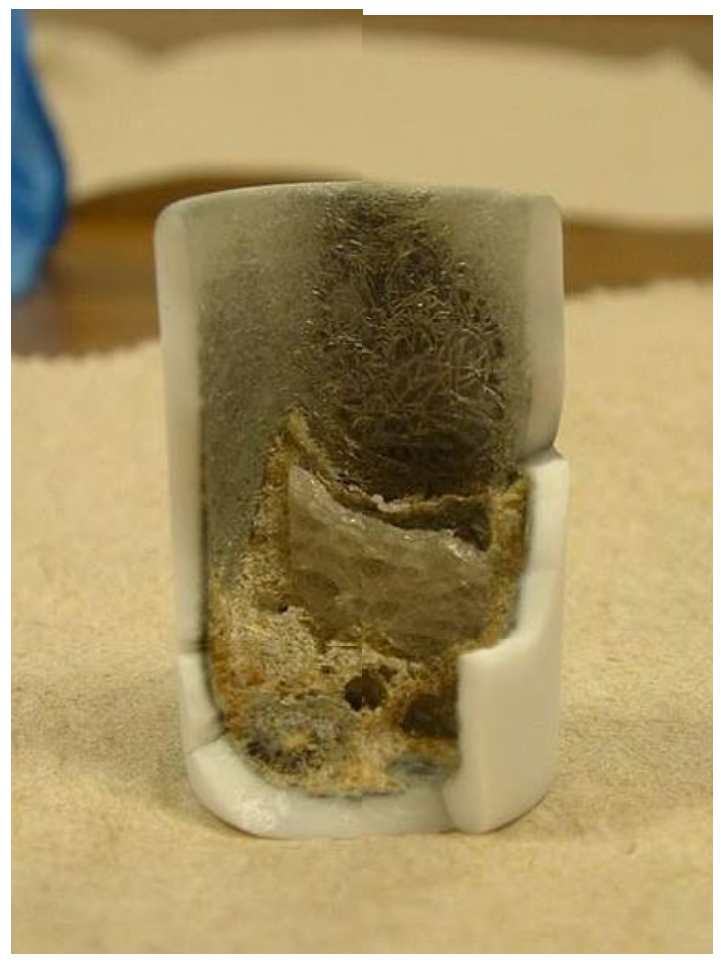

Figure 5.3. Sapphire in coal slag after heat treatment and dissolution of coal slag in HF.

Figure 5.4 is a typical SEM of a cross section of a sapphire sample corroded in coal slag. Sapphire is in the middle and the two straight vertical lines represent interfaces between sapphire and coal slag. Straight lines in this picture indicate that the interface between sapphire and coal slag and clear and that there is no penetration of coal slag into sapphire. Some holes are also evident in coal slag. They are formed from gases in coal slag during the heat treatment that become trapped inside the solid coal slag during cooling. It is possible that the gas bubbles were traveling upward along the sapphire edges during the heat treatment, which resulted in less corrosion than if coal slag molt would have been present around sapphire all the time.

To further analyze if any coal slag penetrated sapphire sample, EDX scans were obtained, shown in Figure 5.5. Four elements were examined: silicon (upper left), iron (upper right), aluminum (lower left) and oxygen (lower right). The right half of each of those quarters is sapphire and the left half is coal slag. Consequently, silicon and iron are only on the left and aluminum is only on the right. Some silicon and iron dots pass into the sapphire half of the picture, but this is probably caused by smearing some coal slag over sapphire while cutting with diamond saw. An interesting aspect of this image is that silicon and iron seem to have separated from each other- exactly the space where there is no Si is occupied by Fe and vice versa. The reason why the iron was accumulated along the sapphire interface is not understood. There are traces of $\mathrm{Si}$ and Fe observed in sapphire part of the scan along one diagonal line. This is probably due to a scratch that was filled with coal slag during cutting of the samples. 


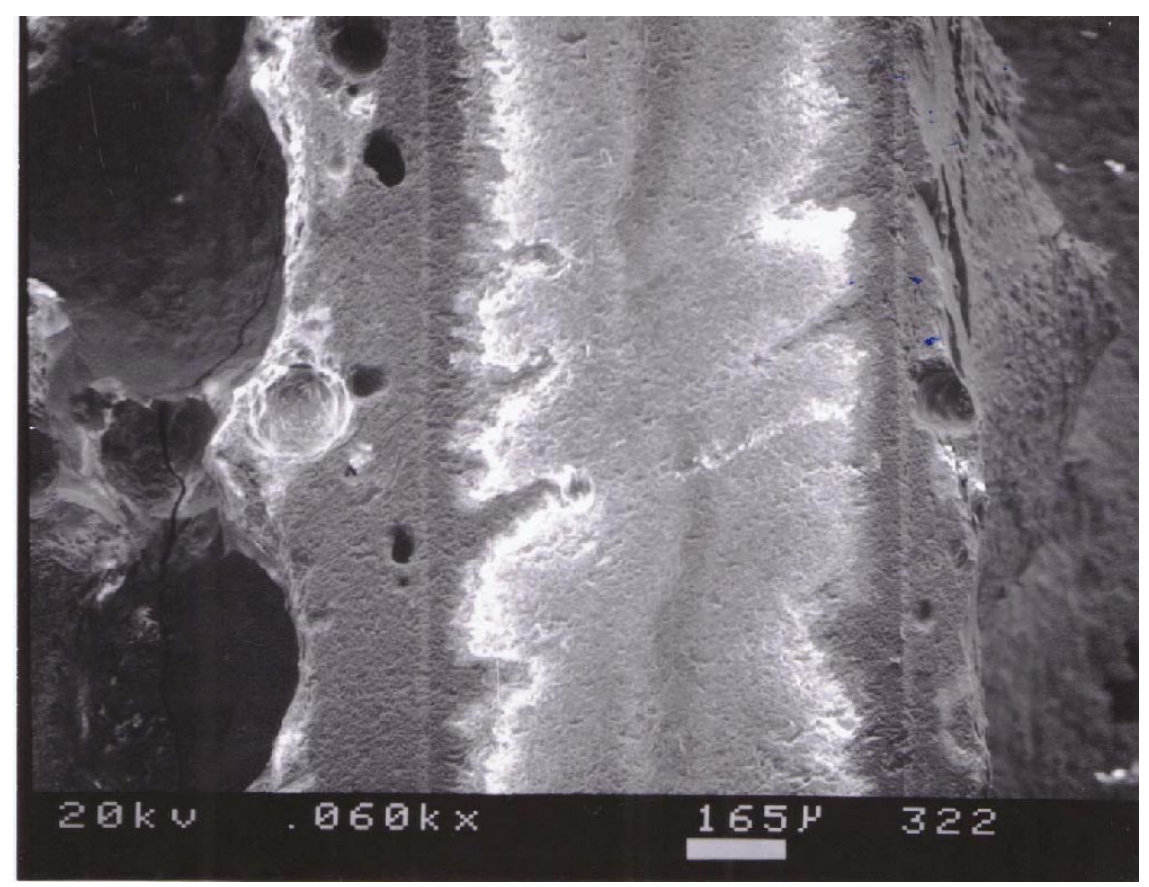

Figure 5.4. Sapphire in coal slag at $1200^{\circ} \mathrm{C}$ for two days.

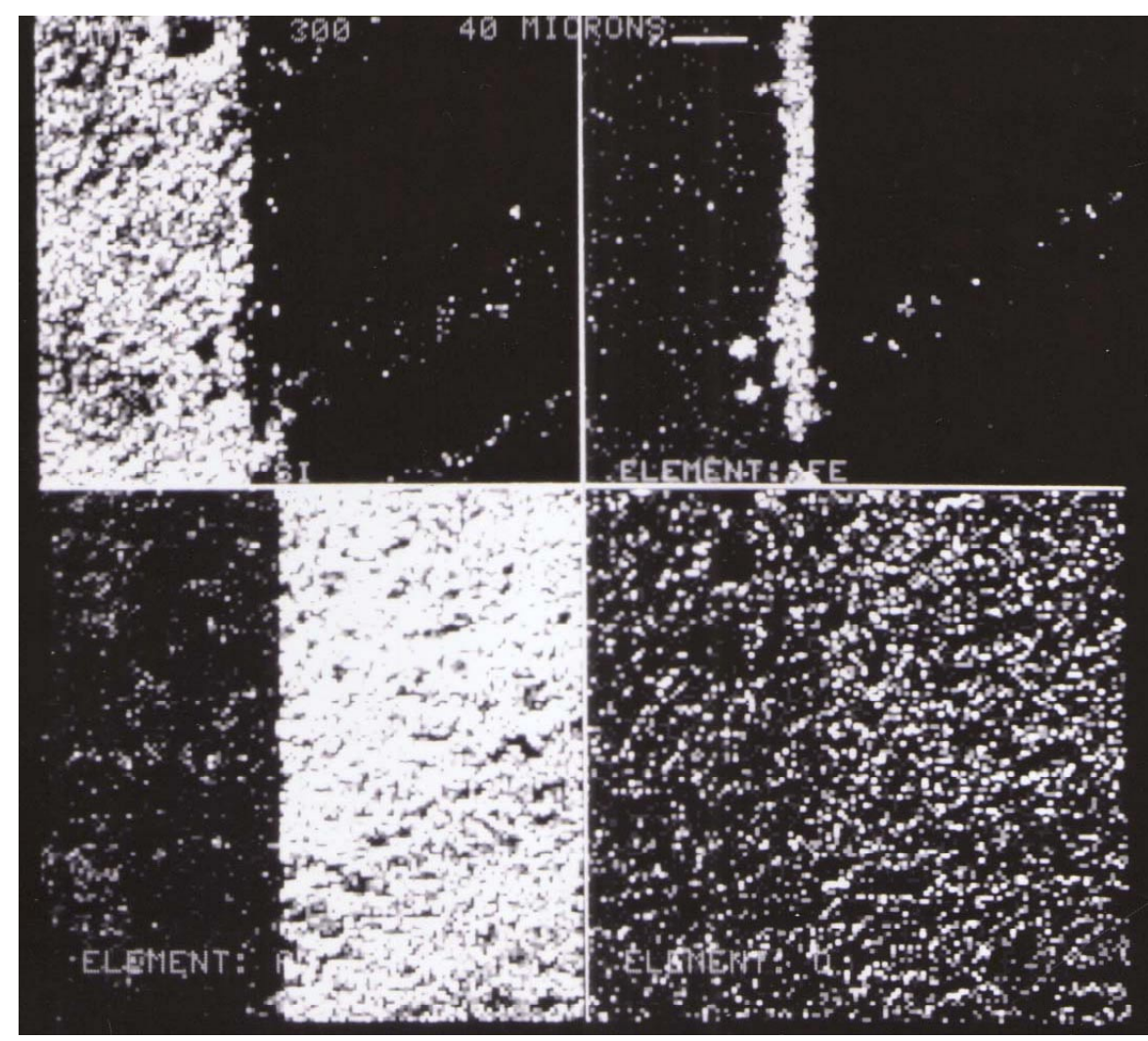

Figure 5.5. EDX image of sapphire in coal slag at $1200^{\circ} \mathrm{C}$ for 2 days, analyzing $\mathrm{Si}$ (upper left), $\mathrm{Fe}$ (upper right), $\mathrm{Al}$ (lower left) and $\mathrm{O}$ (lower right). 


\subsection{Conclusions and Future Work}

The main objective of this project is to bring the BPDI sensor technology, which has already been demonstrated in the laboratory, to a level where the sensor can be deployed in the harsh industrial environments and will become commercially viable. Research efforts were thus focused on analyzing and testing corrosion properties in coal slag at high temperatures. Single crystal sapphire was shown to be resistant to coal slag penetration at temperatures up to $1300^{\circ} \mathrm{C}$. Tests are ongoing at $1400^{\circ} \mathrm{C}$. The mechanical packaging was designed in preparation for a full field demonstration at Global Energy Technology's Wabash River Facility. Ongoing meetings will finalize testing details.

The sensor instrumentation will be designed for continuous operation in an actual coal gasification facility under high temperatures and extremely corrosive conditions. Based on the results shown in this report, future research work will mainly focus on two areas:

\section{$\underline{1 .}$ Further laboratory testing and calibration of the sensor prototype}

Prior to the field ready prototype for actual installation of the temperature sensor system in the gasification unit, the entire system will be tested in the laboratory to ensure proper operation, which will include updating of the software for the whole system. By employing Visual Basic or LabVIEW; a graphical user interface (GUI) will be used to display the data for inspection and the data will also be stored on the hard disk for further analysis. Special consideration will be given to the required mechanical protection of both the sensor probe and the associated signal demodulation system.

\section{Site preparation and installation}

The field test site will be prepared for installation of the sensor system. After all external infrastructure is installed for communication of the signal to an appropriate location, the sensor probe will be installed in the gasifier. The system will be operated for several months to evaluate the performance. The data obtained during the field test will be analyzed to determine the performance of the temperature sensor in the gasification unit. 


\section{References Cited}

1. G. R. Pickrell "High-temperature alkali corrosion kinetics of low-expansion ceramics (alkali corrosion)," Virginia Polytechnic Institute \& State University, Blacksburg, VA, Ph.D. dissertation (1994).

2. M. K. Ferber and V. J. Tennery, "Evaluation of tubular ceramic heat exchanger materials in basic coal ash from coal-oil-mixture combustion," Oak Ridge Natl. Lab. Avail. NTIS, Oak Ridge, TN ORNL/TM-8385; Order No. DE83001700, (1982).

3. G. C. Wei and V. J. Tennery, "Evaluation of tubular ceramic heat exchanger materials in residual-oil-combustion environment.," Oak Ridge Natl. Lab. Avail. NTIS, Oak Ridge, TN ORNL/TM-7578, (1981). 


\section{Bibliography}

1. Y. Zhang, G. R. Pickrell, B. Qi, R. G. May and A. Wang, Single Crystal Sapphire High Temperature Measurement Instrument for Coal Gasification,The 8th Symposium on Temperature: Its Measurement and Application in Science and Industry Conference Proceedings Chicago, pp. (Peer Reviewed) (2002).

2. Y. Zhang, G. R. Pickrell, B. Qi, R. G. May and A. Wang, BPDI based optical temperature sensor for real-time high temperature measurements for the coal gasification process,Photonics Asia, Advanced Sensor Systems and Applications, Proc. SPIE Shanghai, vol. 4920, pp. 4920-2 (2002).

3. Y. Zhang, G. R. Pickrell, B. Qi, R. G. May, and A. Wang, "Optical high temperature measurement instrument with single-crystal sapphire for harsh environment," submitted to J. Lightwave Tech. (2002).

4. Y. Zhang, G. R. Pickrell, and A. Wang, Optical Fiber Single Crystal Sapphire High Temperature Sensing Instrument, Patent Application Filed (2002).

5. B. Qi, G. R. Pickrell, J. Xu, P. Zhang, Y. Duan, W. Peng, Z. Huang, R. G. May, and A. Wang, "High-resolution white light interferometer and its application," submitted to Applied Optics (2001).

6. Y. Zhang, G. Pickrell, B. Qi, R. G. May and A. Wang, Single-crystal sapphire high temperature sensing based on broadband polarimetric interferometer,Sensors for Industry Conference, Proc. IEEE Rosemont, IL, pp. 303-307 (2001).

7. B. Qi, W. Huo, H. Xiao, and A. Wang, Novel Data Processing Method for White Light Interferometric Fiber Optic Sensors, Patent Application Filed (2001).

8. H. Xiao, W. Huo, J. Deng, M. Luo, Z. Wang, R. G. May, and A. Wang, "Fiber optic white light interferometric spectrum signal processing for absolute measurements," Harsh Environment Sensors II, Proc. SPIE 3852, pp. 74-80, Boston (1999).

9. H. Xiao, Y. Xie, J. Deng, R. G. May, and A. Wang, "Absolute sapphire optical fiber interferometric sensors," Process Monitoring with Optical Fibers and Harsh Environment Sensors, Proc. SPIE 3538, pp. 115-121, Boston (1998).

10. H. Xiao, W. Zhao, R. Lockhart, J. Wang, and A. Wang, "Absolute sapphire optical fiber sensor for high-temperature applications," Sensors and Controls for Advanced Manufacturing, Proc. SPIE 3201, pp. 36-42, Pittsburgh (1997).

11. Y. Zhang, G. Pickrell, B. Qi, R. G. May, and A. Wang, "Single-crystal sapphire high temperature sensing based on broadband polarimetric interferometer," Sensors for Industry Conference, Proc. IEEE, pp. 303-307 (2001).

12. X. Fang, R. G. May, A. Wang, and R. O. Claus, "A fiber-optic high temperature sensor," Sens. Act. A 44), 19-24 (1994). 
13. A. Wang, S. Gollapudi, R. G. May, K. A. Murphy, and R. O. Claus, "Sapphire optical fiber-based interferometer for high temperature environmental applications," J. Smart Mat. Struct. 4), 147-151 (1995). 


\section{List of Acronyms and Abbreviations}

$\mathrm{A} / \mathrm{D}$, analog to digital

APP, Advanced Pressure Products, Inc.

BPDI, broadband polarimetric differential interferometry

CCD, charge couple device

CPT, Center for Photonics Technology

CTE, coefficient of thermal expansion

EFPI, extrinsic Fabry-Perot interferometer

EMI, electromagnetic interference

FWHM, full width half maximum

GPM, gallons per minute

GRIN, graded index

LED, light emitting diode

MMF, multimode fiber

OPD, optical path difference

PC, personal computer

PZT, lead zirconium titanate

RFLWN, raised face long weld neck

SCIIB, self-calibrated interferometric/intensity-based

SLED, superluminescent light emitting diode

SMF, single mode fiber

SNR, signal to noise ratio

VTPL, Virginia Tech Photonics Laboratory (now Center for Photonics Technology) 